\title{
Out Come of Topical Phenytoin in the Management of Diabetic Ulcers
}

\author{
Sankar Rao Kodela ${ }^{1}$, T.J.Prasanna Kumar ${ }^{2}$, Dr.Vivek ${ }^{3}$ \\ ${ }^{I}$ Sankar Rao Kodela, Post Graduate Student Of General Surgery, NRI Medical College \& General Hospital, \\ Chinakakani, Guntur Dist, Andhra Pradesh, India. \\ ${ }^{2}$ T.J.Prasanna Kumar, M.S., General Surgery, Professor Of The Department Of General Surgery, NRI Medical \\ College \& General Hospital, Chinakakani, Guntur Dist, Andhra Pradesh, India. \\ ${ }^{3}$ Vivek, M.S., General Surgery, Assistant Professor, NRI Medical College \& General Hospital, Chinakakani, \\ Guntur Dist, Andhra Pradesh, India.
}

\begin{abstract}
:
Aim: To compare the efficacy of topical phenytoin with that of a control group using conventional wound dressings, in healing of diabetic ulcers, in terms of: Number of days required for healing, Rate of granulations tissue formation, Rate of reduction in mean ulcer surface area, Quality of graft bed, Skin graft take up, Serial culture and sensitivity of wound swabs to assess the effect of topical phenytoin on bacterial load.

Study design: Randomized control trial.

Place and duration of study: General Surgery Department, NRI Medical College \& General Hospital, Chinakakani from October 2013 to September 2015.

Methodology: 100 patients with chronic wounds, of varying etiology, admitted in NRI Medical College \& General Hospital, Chinakakani from October 2013 to September 2015. The patients with chronic ulcers with Type II Diabetes mellitus. Wound size <5\% TBSA. The whole sample population was divided into two equal and comparable groups based on willingness for undergoing topical phenytoin therapy for wound. Those who were not willing were subjected to conventional wound care, forming the control group.

Results: Rate of granulation tissue was more rapid in phenytoin group as compared to conventional moist dressing group i.e. mean $85.21 \%$ for phenytoin group and mean $70.32 \%$ for conventional moist dressing. Hospital stay was reduced in phenytoin group compared to conventional moist dressing group i.e mean 30.04 days for phenytoin group and mean 45.10 days for conventional moist dressing group. Percentage of graft uptake is more in phenytoin group compared to conventional moist dressing group i.e. mean $91.78 \%$ for phenytoin group and mean $75.48 \%$ for conventional moist dressing group

Conclusion: To conclude, that the overall hospital stay and post operative complications were less in the topical phenytoin dressing group. Thus, topical phenytoin moist wound dressing can be considered as a superior option in the management of diabetic ulcers.
\end{abstract}

Keywords: chronic wounds, phynytoin, vascularity, dressing.

\section{Introduction}

Patients with diabetes are at increased risk for foot ulcers ${ }^{1}$. The prevalence of foot ulcers among patients with diabetes is 12 percent $^{2}$. These ulcers are associated with high financial cost, long term morbidity, and sometimes even mortality. Diabetic foot ulcers are associated with slow wound healing and an increased susceptibility to infection. Primary closure of the ulcer is often difficult. Wound closure by split thickness skin graft (STSG) is often the simplest and most versatile method of wound management. Development of granulation tissue in the wound is important requirement for successful skin grafting. Granulation tissue has a high level of vascularity resulting from abundance of new capillary formation. This degree of vascularity enables granulation tissue to accept skin grafts ${ }^{3}$.

Diabetic wounds are a significant healthcare problem with its healing depends on many factors such as glycemic control, vascularity, bacterial load, location of the wound, nutritional status of the patient ${ }^{4.5}$ Many agents have been tried in wound healing, one such agent is phenytoin. Phenytoin (diphenylhydantoin) was introduced into therapy in 1937 for effective control of convulsive disorders ${ }^{6,7}$ with a common side effect being gingival hyperplasia ${ }^{8}$. This stimulatory effect of phenytoin on connective tissue suggested possibility for its use in wound healing. The beneficial effect of phenytoin has been shown in promoting healing of decubitus ulcers ${ }^{9,10}$, venous stasis ulcers ${ }^{11}$, traumatic wounds ${ }^{12,13}$, burns $^{14}$, leprosy trophic ulcers ${ }^{15}$. The present study was conducted to assess the efficacy of topical phenytoin dressing as compared to conventional moist wound dressing in the healing process of diabetic ulcers and to check whether it is a better alternative in the management of diabetic ulcers. 
Chronic diabetic foot ulcers remain difficult to manage. Topical application of phenytoin has been used successfully in the management of diabetic foot ulcers ${ }^{16,17}$. It stimulates the development of granulation tissue formation within 2 to 7 days after beginning treatment and is associated with non-detectable serum phenytoin levels ${ }^{10,18}$. Almost all of the reports on phenytoin and wound healing used the powder form. Because of its dry nature, wound treatment with phenytoin powder is limited to wet wounds. Moisture is important for granulation tissue formation ${ }^{19}$.

Prevalence of diabetic foot ulcer in clinical population is $3.61 \%$. Diabetic foot ulcers precede almost $85 \%$ of amputations in India $^{20}$. Management of the diabetic foot requires a multisystem approach, which includes the nervous, vascular, skeletal, immune, and integumentary systems ${ }^{21}$ The pathophysiological changes in multiple organ systems are the result of metabolic dysregulation associated with diabetes mellitus, imposes tremendous burden on individual ${ }^{22}$. For many decades, various different techniques have been tried to treat chronic leg ulcers, but none was proved to be ideal dressing. Phenytoin has been used by many workers because of its positive effects in ulcer healing, such as increase in the proliferation of fibroblasts and deposition of collagen, neovascularization, enhanced granulation tissue formation, decrease in the action of collagenase and bacterial contamination ${ }^{23-27}$. The antibacterial activity of phenytoin contributed to removal of Staphylococcus aureus, Escherichia coli, Klebsiella species, Pseudomonas, ${ }^{9,20,28}$. Since some authors have reported use of phenytoin in healing of different ulcers including diabetic foot ulcer, it prompted us to conduct a study on the local use of phenytoin on diabetic foot ulcer healing.

Diabetic foot ulcers (DFUs) are extremely debilitating and difficult to treat. Multidisciplinary management, patient education, glucose control, debridement, offloading, infection control, and adequate perfusion are the mainstays of standard care endorsed by most practice guidelines. Adjunctive therapies represent new treatment modalities endorsed in recent years, though many lack significant high-powered studies to support their use as standard of care. ${ }^{18}$

Non-healing or chronic wounds are a significant healthcare problem today; the quest for better woundhealing agents is perhaps one of the oldest challenges for medical practice. One such agent that has been tried in wound healing is phenytoin. Phenytoin (diphenylhydantoin) was introduced into therapy in 1937 for the effective control of convulsive disorders. A common side effect with phenytoin treatment for epilepsy is the development of fibrous overgrowth of gingiva, although mild skin and skull thickening may also occur. This apparent stimulatory effect of phenytoin on connective tissue suggested an exciting possibility for its use in wound healing. ${ }^{18}$

Phenytoin has been used topically for many years to enhance the healing of chronic wounds ${ }^{30}$. Its wound healing promoting effect has been attributed to many mechanisms, including increasing fibroblast proliferation, inhibiting collagenase activity, promoting collagen disposition, enhancing granulation tissue formation, decreasing bacterial contamination, reducing wound exudate formation, and up-regulating growthfactor receptors ${ }^{23-27,31}$

The purpose of this study was to evaluate the effect of phenytoin tablet on the rate of split thickness skin autograft survival in patients with large diabetic foot ulcers.

\section{Aims And Objectives}

- To compare the efficacy of topical phenytoin with that of a control group using conventional wound dressings ,in healing of diabetic ulcers, in terms of:

- Number of days required for healing.

- Rate of granulations tissue formation.

- Rate of reduction in mean ulcer surface area.

- Quality of graft bed.

- Skin graft take up.

- Serial culture and sensitivity of wound swabs to assess the effect of topical phenytoin on bacterial load.

\section{Materials And Methods}

This prospective randomized comparative study included 100 patients with chronic wounds, of varying etiology, admitted in NRI Medical College \& General Hospital, Chinakakani from October 2013 to September 2015 satisfying all the inclusion criteria mentioned below, after the clearance from the ethical committee was obtained. All chronic wounds where conventional dressings are indicated were included in the study.

\subsection{Inclusion criteria}

- $\quad$ Patients with age between 25 - 60 years

- Patients with chronic ulcers with Type II Diabetes mellitus. Wound size $<5 \%$ TBSA

- Patients giving consent for topical phenytoin therapy. 


\subsection{Exclusion criteria}

- Chronic non-healing wounds of other aetiology.

- Diabetes mellitus with gangrenous changes.

- Other co-morbid condition like renal failure, generalized debility and other factors, which adversely affect wound healing.

- History of phenytoin intake by patients

- Immunocompromised

Routine pre-operative investigations were done in both the groups. Necessary debridement was done in all the cases. Culture and sensitivity swabs were taken from all the cases and sent for microbiological evaluation before start of the study. The required patients were treated with appropriate systemic antibiotics as per culture and sensitivity reports. Usual anti-diabetic treatment was continued in all patients. After slough removal, the surface area was measured with vernier Callipers. On each occasion, ulcer areas were measured twice. All the measurements were carried on by a single examiner for all the participants. Gentle saline cleaning and topical phenytoin in study group and conventional moist dressing in control group applied twice daily for a period of 14 days or until complete healing. Patients from both the study and control groups were compared for final analyses. Phenytoin dose estimation was done, based on the surface area. Dosage used was for, $0-5 \mathrm{~cm}^{2} \rightarrow 100$ $\mathrm{mg}, 5.1-9 \mathrm{~cm}^{2} \rightarrow 150 \mathrm{mg}, 9.1-15 \mathrm{~cm}^{2} \rightarrow 200 \mathrm{mg},>15 \mathrm{~cm}^{2} \rightarrow 300 \mathrm{mg}$ respectively. Phenytoin powder was mixed with normal saline and applied with gauze, as was described by Rhodes ${ }^{10}$.

Patients with grade III, IV and V diabetic foot ulcers, diabetic ulcers with ischaemic changes, tropic ulcers caused by neuropathy, multiple sclerosis, varicose ulcers, Marjolin's ulcers were excluded.

The data was collected from 100 patients who are having diabetic ulcers satisfying all the inclusion criteria mentioned above. The whole sample population was divided into two equal and comparable groups based on willingness for undergoing topical phenytoin therapy for wound. Those who were not willing were subjected to conventional wound care, forming the control group.

All patients underwent detailed clinical examination and relevant investigations and the wounds were thoroughly debrided and the ulcer dimensions as well as the surface area assessed using vernier calipers, before both types of dressings were applied. The patients were followed up on a daily basis for 14 days in both study and control groups. The control group and study group were subjected to twice-daily dressing.

A single $100 \mathrm{mg}$ phenytoin sodium tablet mixed with $5 \mathrm{ml}$ of sterile normal saline to form a suspension. Sterile gauze was soaked in the suspension and placed over the wound at $20 \mathrm{mg} / \mathrm{cm}^{2}$ TBSA. Conventional Dressing was done with $5 \%$ w/v povidone - iodine solution. Before applying the dressing, the wound was cleaned with normal saline. At the end of 14 days the wounds in both the groups were inspected and the wounds were compared based on the following parameters. They were:

(1) Rate of granulation tissue formation as percentage of the ulcer surface Area;

(2) Quality of ulcer bed;

(3) Present dimensions and surface area of the ulcer.

Once these parameters were assessed, both the groups were subjected to split thickness skin grafting. Both the groups were given the same systemic antibiotics (ceftriaxone $1 \mathrm{~g}$ intra-venous for 5 7 days with metronidazole $100 \mathrm{ml}$ t.id. for 3 days) during the postoperative period. The wounds were reassessed at the end of the fifth postoperative day and wounds were compared based on the following parameters. They were:

(1) Skin graft take-up as a percentage of ulcer surface area,

(2) Number of days of hospitalization.

The follow-up of these patients was done in the out-patient department after one month of discharge to assess post skin grafting complications like contractures, itching, pain and infection, wound dimensions. The results obtained were statistically evaluated based on the following parameters.

\section{They were:}

(1) Rate of granulation tissue formation,

(2) Graft survival and take up,

(3) Duration of hospital stay.

The mean rate of granulation tissue formation, graft survival and hospital stay was calculated and compared for both groups. The variables were compared using the Unpaired Student's t-test. A "P" value $<0.05$ was considered significant.

\subsection{Materials used}

Phenytoin tabs powder 


\subsection{Statistical Analysis:}

- The data was collected, compiled \& analysed using SPSS v16.0.

- The primary measure of efficacy was the reduction in the surface area of the ulcer. The mean ulcer surface area was determined before, during and after treatment. The student unpaired ' $t$ ' test compared the reduction in ulcer areas between the two treatment groups . Level of significance was chosen at $\mathrm{P}<0.05$.

\section{Observation And Results}

The 100 patients admitted in the study were divided into two equal and comparable groups. Patients subjected to topical phenytoin dressing were classified as cases and those who underwent conventional wound dressing (Povidine Iodine) were classified as controls.

Table 1: Age distribution of patients who underwent surgeries

\begin{tabular}{|c|c|c|}
\hline Age in Years & Study Group & Control Group \\
\hline $25-35$ & 4 & 5 \\
\hline $36-45$ & 16 & 13 \\
\hline $46-55$ & 19 & 14 \\
\hline $56-60$ & 11 & 18 \\
\hline
\end{tabular}

The mean age of study group was $47.28 \pm 12.49$ years and that of control group was $49.20 \pm 10.9$ years

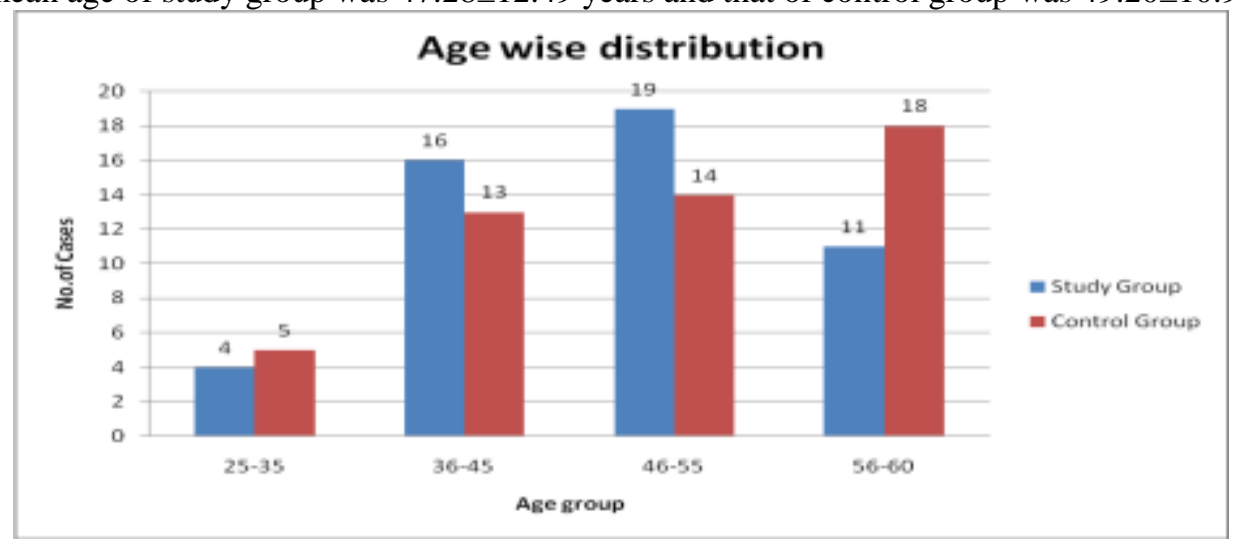

Table 2: Sex distribution in patients who underwent surgeries

\begin{tabular}{|l|l|l|l|l|l|l|l|}
\hline & & Male & Female & & \\
\hline & & & & & & \\
\hline & & & 28 & 22 & & \\
\hline & & & & & & \\
\hline & & Control & 35 & & & & \\
\hline
\end{tabular}

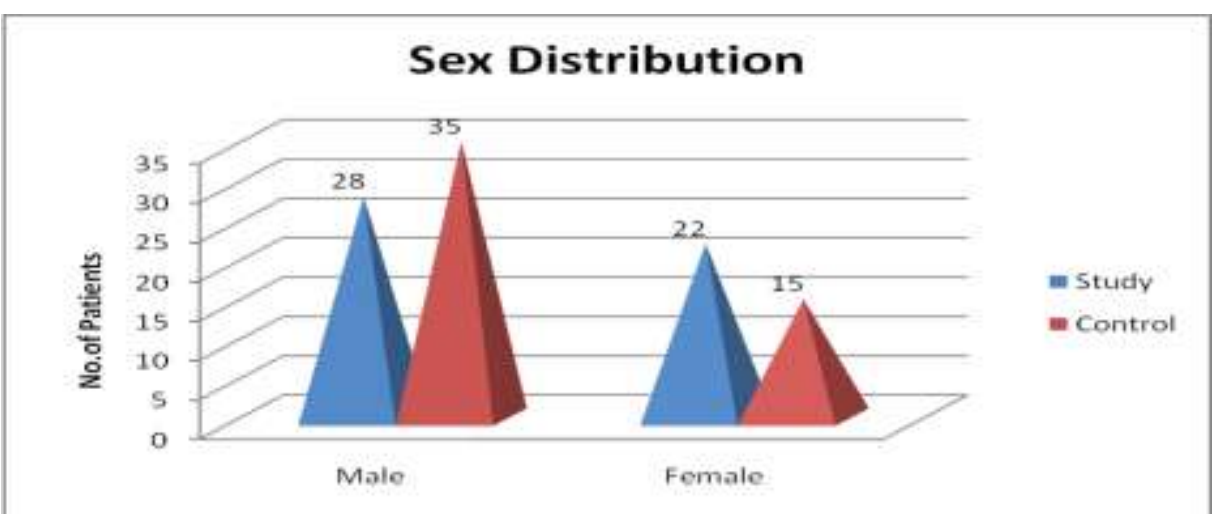

In both study and control groups, diabetes was more common among males as compared to females. Among them, $63 \%$ of the patients were males and $37 \%$ were females.

Table 3: Rate Of Granulation

\begin{tabular}{|l|l|l|}
\hline Granulation in \% of ulcer area & Study & Control \\
\hline & & \\
\hline$<40$ & 1 & 9 \\
\hline
\end{tabular}




\begin{tabular}{|l|l|l|l|}
\hline & & & \\
\hline 41 & -50 & 1 & 7 \\
\hline & & & \\
\hline 51 & -60 & 2 & 4 \\
\hline & & & \\
\hline 61 & -70 & 1 & 4 \\
\hline & & & \\
\hline 71 & -80 & 1 & 3 \\
\hline & & & \\
\hline 81 & -90 & 34 & 8 \\
\hline & & & \\
\hline$>90$ & & 10 & 15 \\
\hline
\end{tabular}

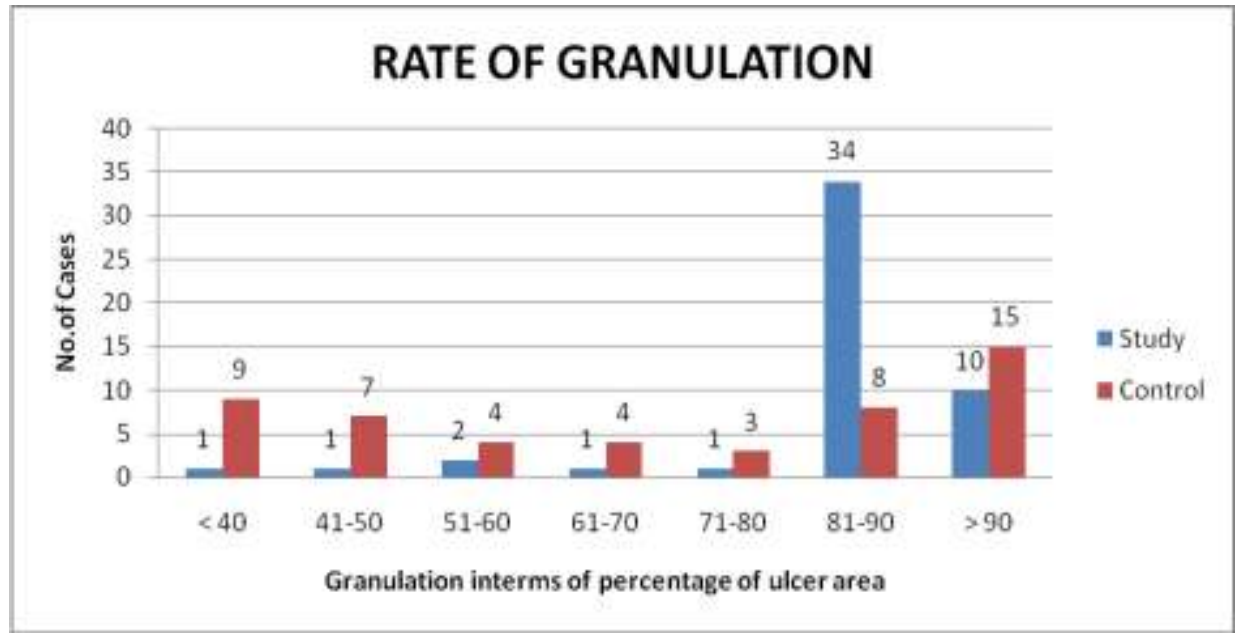

The rate of granulation tissue formation was assessed at the end of 2 weeks. 81 to $90 \%$ granulation was seen in study group. The patients in both the groups were subjected to split thickness skin graft as the final treatment modality. The graft take up was assessed on the fifth post operative day.

Table 4: Duration Of Hospital Stay

\begin{tabular}{|l|l|l|}
\hline & Mean & SD \\
\hline Study & & \\
\hline & 30.04 & 9.141 \\
\hline Control & & \\
\hline
\end{tabular}

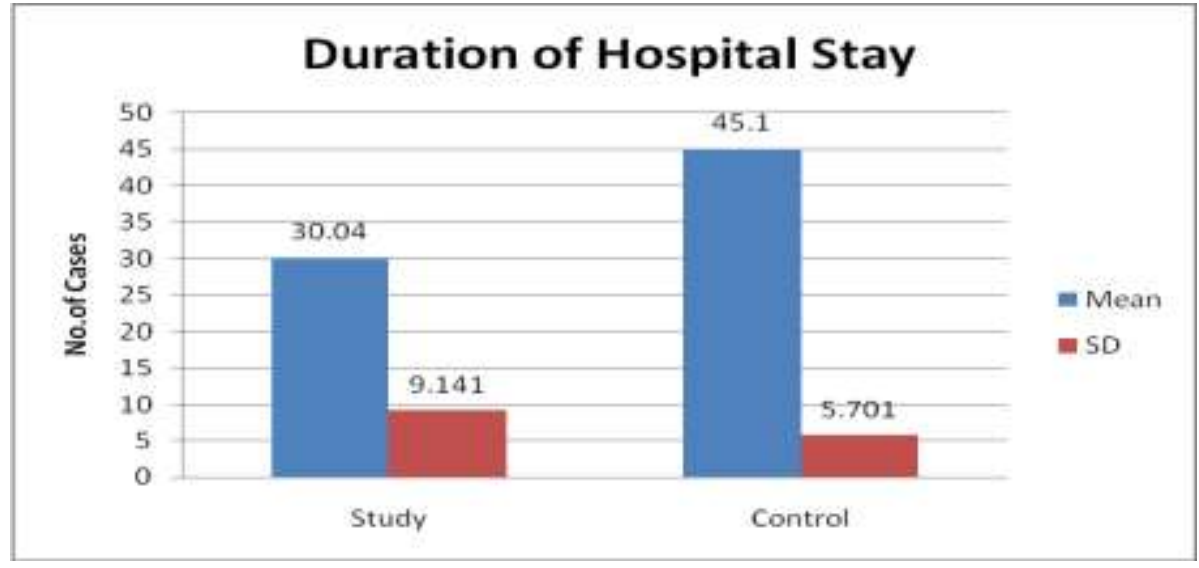

The duration of hospital stay was prolonged in patient in the control group. The mean duration of stay for patient with diabetic foot using phenytoin topical application was 30.04 days for the control group it is 45.10 days. This also shows the economic burden on the family.

Table 5: Organisms Isolated From Wound

\begin{tabular}{|c|c|c|}
\hline Organisms & Study Group & Control Group \\
\hline Streptococcus & 2 & 1 \\
\hline Proteus & 2 & 5 \\
\hline Klebsiella & 3 & 2 \\
\hline
\end{tabular}




\begin{tabular}{|c|c|c|}
\hline Citrobacter & 2 & 1 \\
\hline Psuedomonas & 5 & 5 \\
\hline E.Coli & 10 & 8 \\
\hline Staphylococcus aureus & 22 & 23 \\
\hline Sterile & 4 & 5 \\
\hline
\end{tabular}

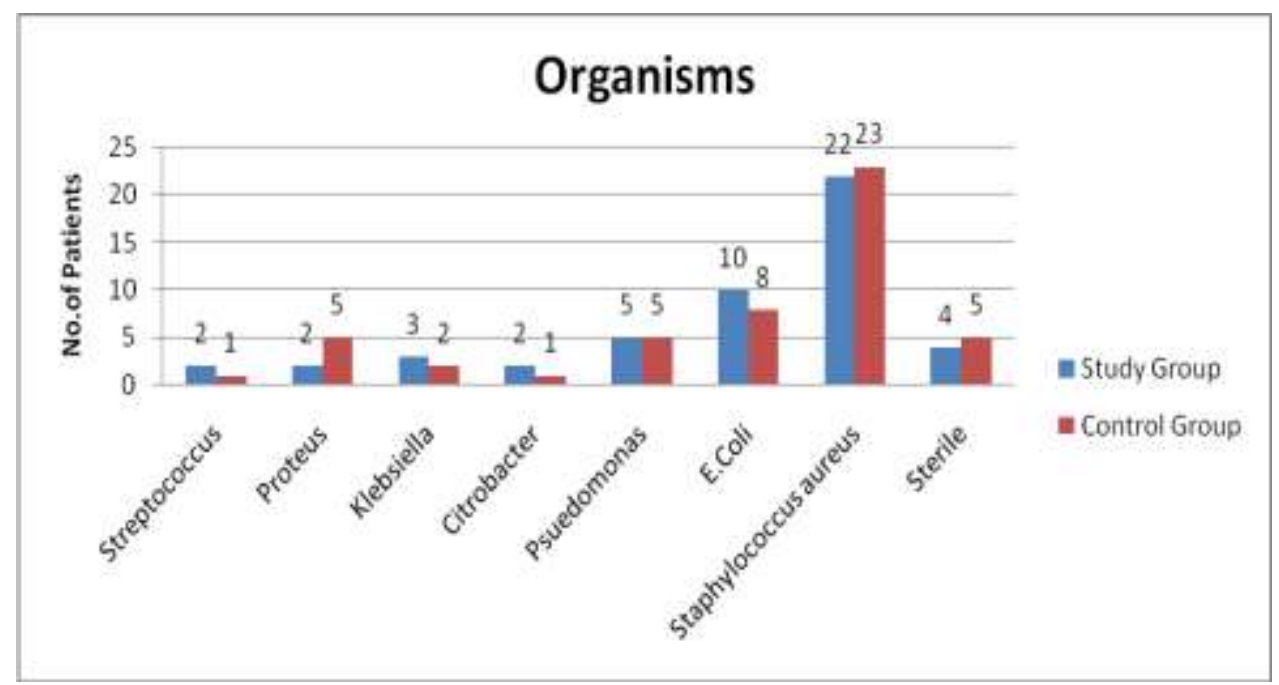

The microbiological evaluation of the wounds in both phenytoin and control groups revealed that Staphylococcus aureus was commonest organism. The other organisms isolated from both cases and controls have been shown in the table. The mean duration of hospital stay in phenytoin group was 30.04 (9.141) days, whereas in control group, it was 45.10 (5.701) days. This difference was statistically significant (Chi-square $=$ 25.62 , p value $<0.005$, df 1 ). Phenytoin application showed no complications topically, except mild itching in 5 cases, which was relieved by antihistamines.

Table 6: Percentage Of Negative Culture Sensitivity At The End Of 14 Days

\begin{tabular}{|c|c|c|}
\hline & Positive & Negative \\
\hline Study & 20 & 30 \\
\hline & & 17 \\
\hline Control & 33 & 17 \\
\hline
\end{tabular}

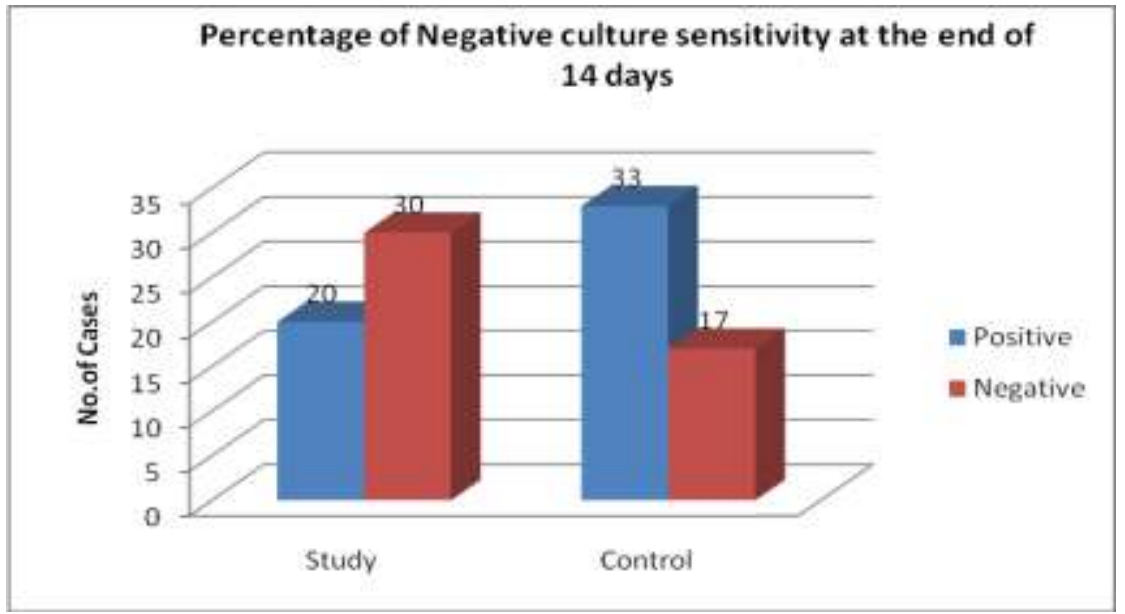

The patients in both the groups were assessed for culture sensitivity at 14 days to determine the effect of topical agents on the bacterial load. $60 \%$ of the study group showed negative culture sensitivity at the end of 14 days, whereas in the control group it was 34\%. In both the groups, no complications occurred during the application of dressings, skin grafting or in the post operative period. The patients were followed up after 1 month of discharge. The main post operative parameters noted in both the groups during follow up were: wound size, contractures, pain, infections. All these parameters were lower in the study group as compared to the control group. 
Table 7: Comparison Of Different Parameters Between Study And Control Group

\begin{tabular}{|l|c|c|c|c|}
\hline \multirow{2}{*}{ Parameter } & \multicolumn{2}{c|}{ Study Group } & \multicolumn{2}{c|}{ Control Group } \\
\cline { 2 - 5 } & Mean & SD & Mean & SD \\
\hline Age & 47.28 & 12.49 & 49.20 & 10.9 \\
\hline Duration of hospital stay & 30.04 & 3.11 & 45.10 & 5.70 \\
\hline $\begin{array}{l}\text { Granulation as \% of ulcer } \\
\text { area }\end{array}$ & 85.21 & 6.98 & 70.32 & 7.91 \\
\hline Average graft take up & 91.78 & 5.41 & 75.48 & 6.91 \\
\hline
\end{tabular}
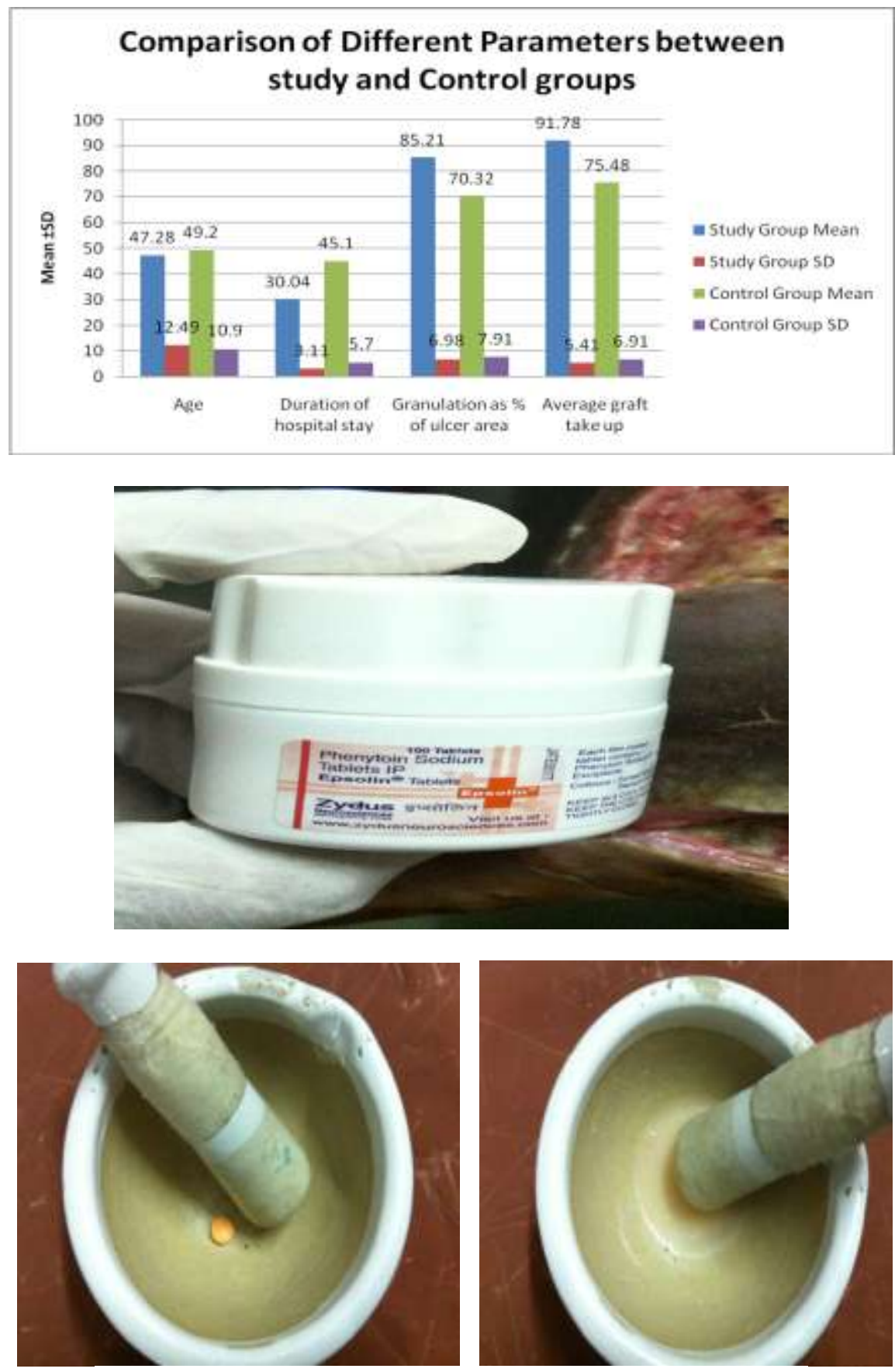

Phenytoin Sodium $100 \mathrm{mg}$ tablet mixing in $5 \mathrm{ml}$ of Normal Saline Study Group 

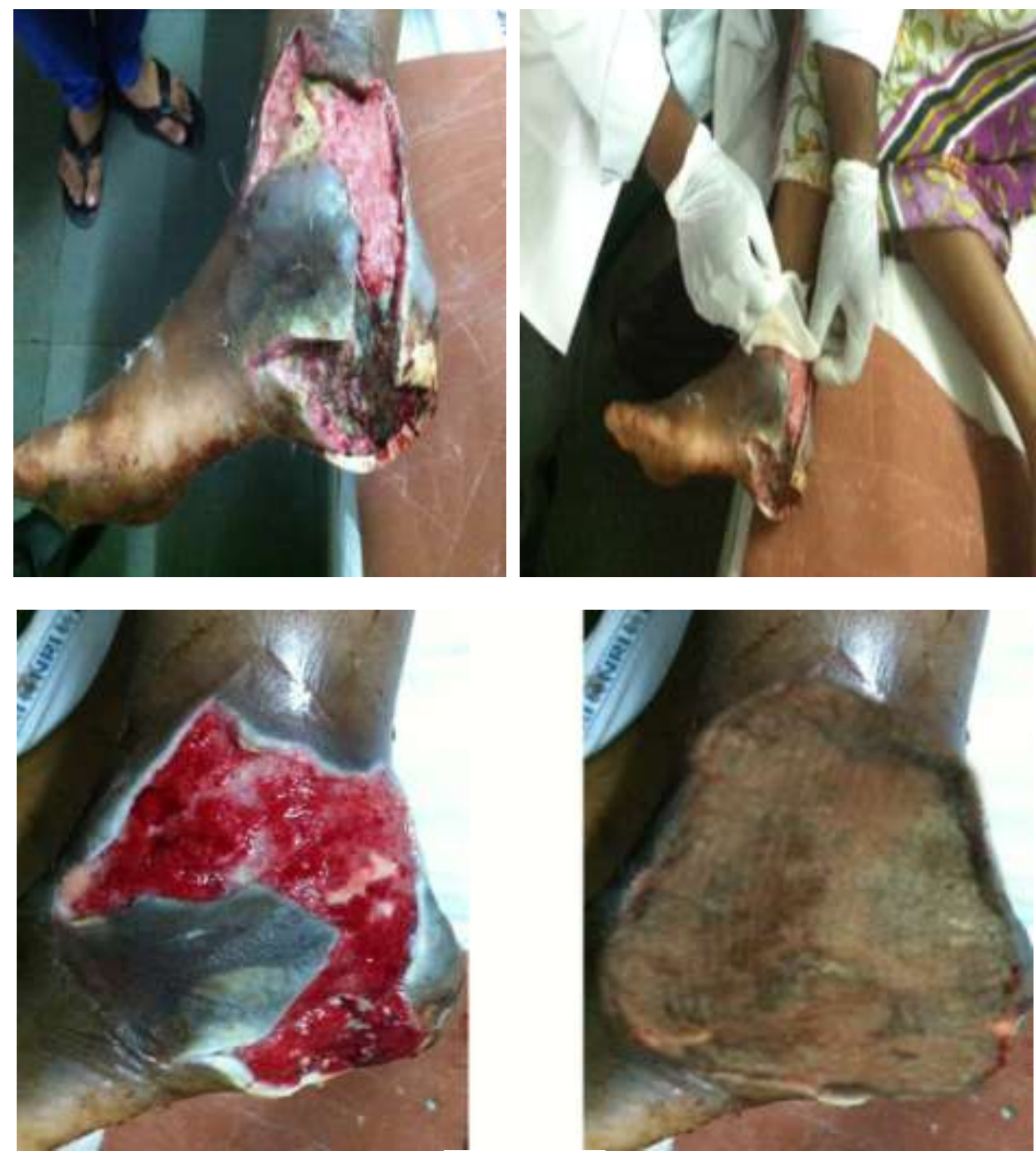

Study Group
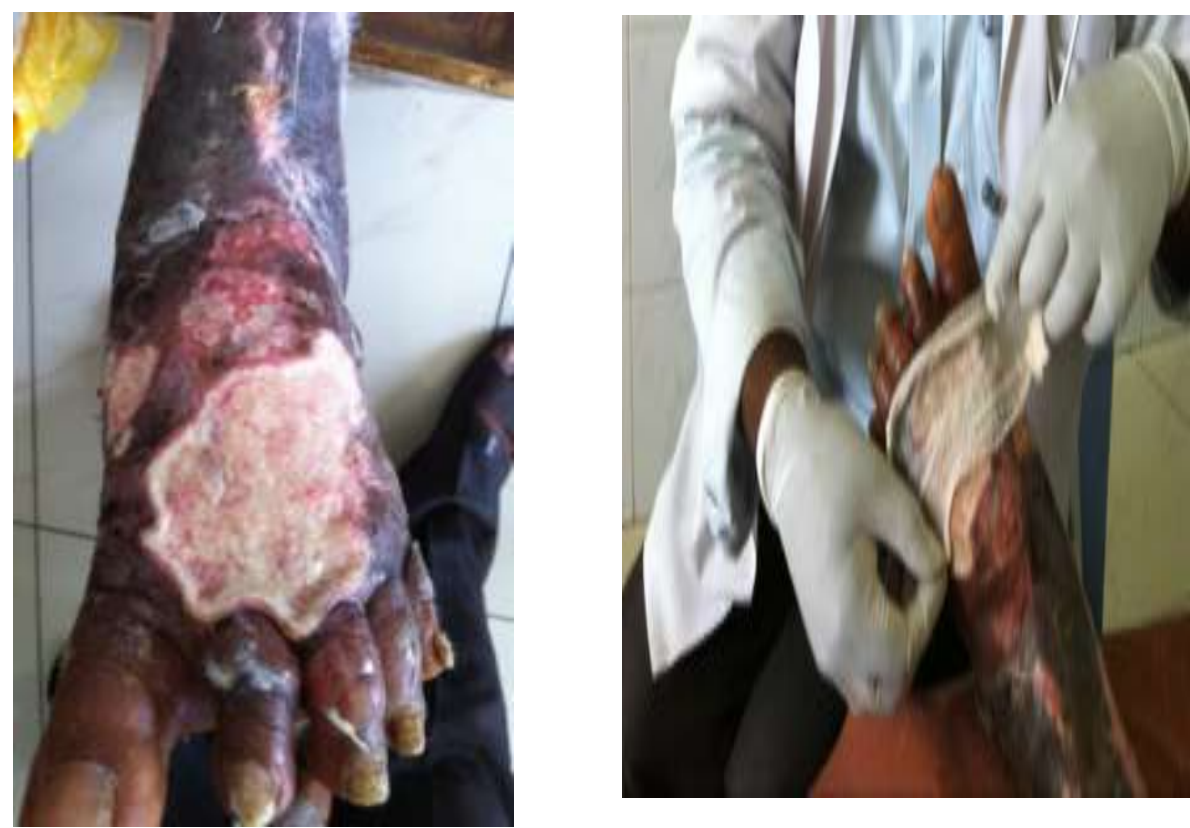

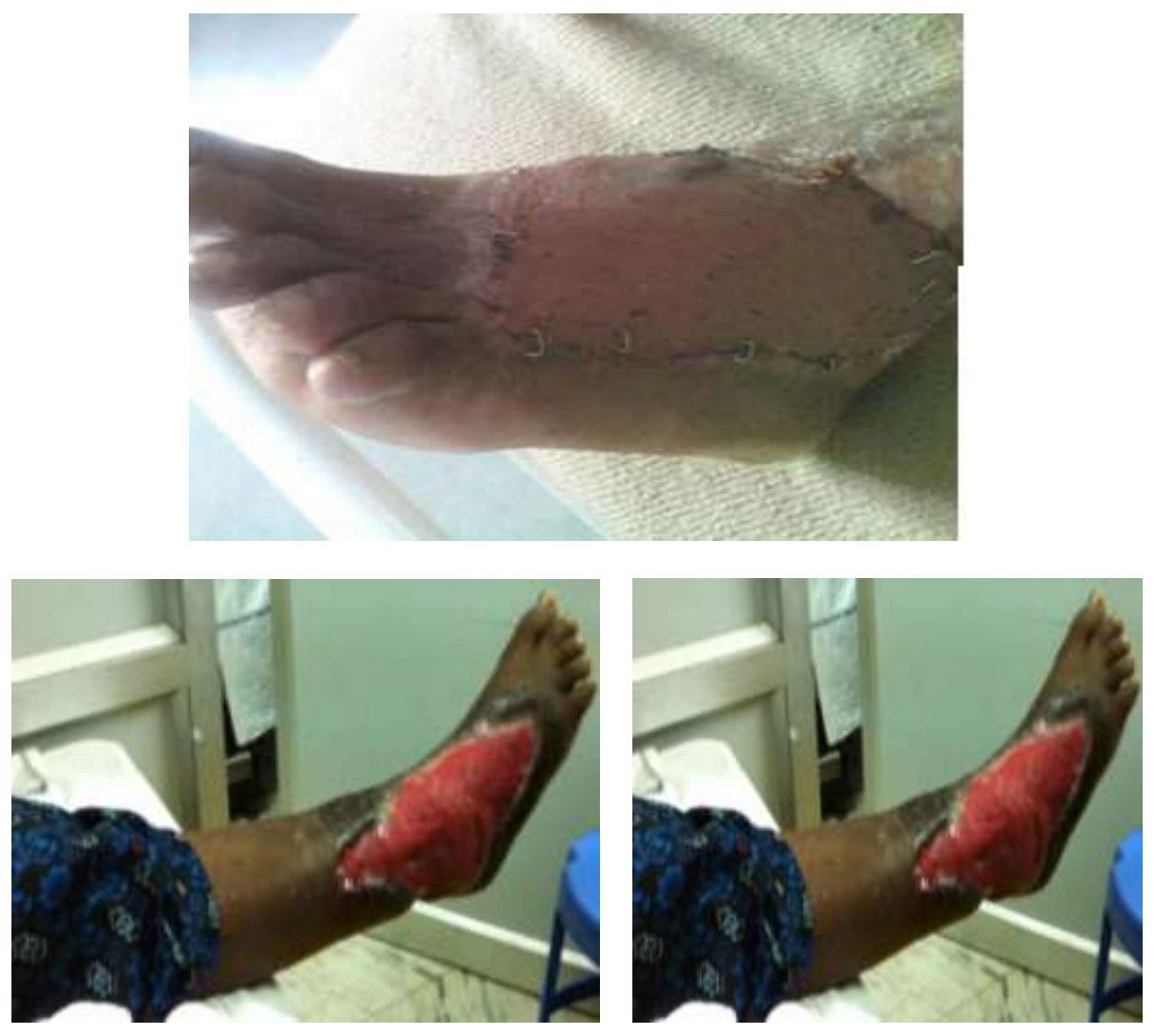

\section{Discussion}

Phenytoin has been investigated as a treatment for more than 100 diseases. Numerous allergy and proliferative, idiosyncratic cutaneous side effects have been reported with its use ${ }^{6}$

In 1938, Merritt and Putnam published their noteworthy data using phenytoin to treat major, absence, and psychic equivalent seizures. Since that time, phenytoin (diphenylhydantoin or Dilantin) has been demonstrated to be a highly effective anticonvulsant. Even decades later, it continues to be a widely prescribed anticonvulsant and antiarrhythmic agent in the treatment of grand mal and psychomotor epilepsy. It is part of the hydantoin family that includes mephenytoin (Mesantoin), phenylethylhydantoin (Nirvanol), and fosphenytoin. ${ }^{6}$ A Medline search in November of 2002 showed that 12,860 articles concerning Phenytoin have been published since 1966. In dermatology, phenytoin has been investigated to treat ulcers, epidermolysis bullosa, and inflammatory conditions.

\section{Ulcers}

Phenytoin has been studied (mostly with inadequate controls) in the healing of pressure ulcers, venous stasis ulcers, diabetic ulcers, traumatic wounds, and burns. ${ }^{16}$ Used topically, it appears to enhance healing without side effects. Its wound-related pharmacology has been investigated. ${ }^{81}$ Phenytoin increases gene expression of the platelet-derived growth factor B chain in macrophages and monocytes. ${ }^{82}$ Healthy granulation tissue appears earlier with phenytoin than with conventional saline dressings. ${ }^{13}$ Phenytoin may promote wound healing through multiple mechanisms, including stimulation of fibroblast proliferation, facilitation of collagen deposition, glucocorticoid antagonism, and antibacterial activity. ${ }^{61}$

Phenytoin seems promising in enhancing the healing of decubitus ulcers. ${ }^{83}$ In a comparison involving 47 patients with stage II decubitus ulcers, treatment with phenytoin, DuoDerm ${ }^{\circledR}$ dressings or triple antibiotic ointment applications all resulted in reduction of the ulcers. However, the phenytoin group demonstrated more rapid results in all aspects of ulcer healing. ${ }^{84}$ Similarly, one study suggests that phenytoin may be superior to honey as a topical agent in the treatment of chronic ulcers. ${ }^{17}$

Phenytoin has been used to treat ulcers that result from mycobacterial infections. It has been used orally and topically to treat the trophic ulcers of leprosy ${ }^{47,49}$ In such a role, it is more effective than saline ${ }^{46 .}$ It can be used in the treatment of the Buruli ulcer of Mycobacterium ulcerans.

Topical phenytoin was used with good effect during the Iran-Iraq war when other resources were limited. In Iran, it was reported to have a role in treating 19 wounds caused by missiles and 6 refractory ulcers in civilians. ${ }^{12}$ In Iraq, it was reported that topical phenytoin in the treatment of war-related decubitus ulcers resulted in prompt pain relief, decreased wound exudate and bacterial contamination, in enhanced granulation- 
tissue formation, and in more rapid healing ${ }^{9}$.Such results might make phenytoin a useful agent in countries with limited access to more expensive wound-care therapies.

There are a few common cutaneous side effects of phenytoin. About 50 percent of patients on longterm phenytoin therapy develop gingival hyperplasia. Long-term phenytoin can lead to a coarsening of the facies, enlargement of the lips, and thickening of the scalp and face ${ }^{85}$. These changes occur in one-third of institutionalized patients on long-term therap $y^{86}$. Coarse facies develop in one phenytoin-treated sister of each of two pairs of identical twins ${ }^{87}$.

Phenytoin can also cause hirsutism. ${ }^{88}$ It occurs in about 12 percent of children receiving phenytoin, usually within 3 months of initiating therapy. ${ }^{89}$ It occurs on the extensor surfaces of the extremities and on the trunk and face. It usually resolves within 1 year of discontinuing therapy but sometimes does not.

A frequent observed and unwanted side effect of phenytoin, an anticonvulsant medication, is gingival hyperplasia, especially in children on long term Phenytoin therapy(more than 4 years). ${ }^{8}$

This side effect suggested that phenytoin can induce the growth of connective tissue, and may have the ability to promote wound healing. In 1939 Kimball and Horan first observed that gingival hyperplasia occurred in some patient s treated with phenytoin. This stimulated the first controlled clinical trial in 1958, which found that the periodontal patients with surgical wounds who were pretreated with oral phenytoin had less inflammation, less pain, and accelerated healing when compared with controls.

The earliest clinical study of phenytoin in cutaneous wound healing used oral phenytoin sodium to treat venous stasis ulcers in 28 patients in a double-blind, placebo-controlled trial ${ }^{30}$.

\section{Topical Phenytoin Mechanism Of Action:}

- Stimulation of fibroblast proliferation,

- enhancing the formation of granulation tissue,

- decreasing collagenase activity,

- inhibition of glucocorticoid activity,

- direct or indirect antibacterial activity by affecting inflammatory cells,

- neovascularisation and phenytoin increases gene expression of the platelet derived growth factor $\beta$ chain in macrophage and monocytes.

A number of clinical studies indicate that phenytoin decreases the bacterial load of wounds. It is not known if phenytoin has intrinsic antibacterial activity, or whether the effect of phenytoin on the bacterial load of wounds is mediated indirectly by effects on inflammatory cells and neovascularisation.

Local pain relief has also been observed with topical phenytoin therapy, which can be explained by its membrane-stabilizing action and the reduced inflammatory response.

\section{Pathogenesis Of Diabetic Foot}

There are 4 main causes for development of foot lesion in a diabetic.

1. Peripheral Neuropathy.

2. Peripheral Vascular disease (PVD).

3. Charcot foot.

4. Infection.

Diabetes mellitus apart from other pathologies primarily affects the vessels \& nerves causing vasculopathy and neuropathy.

The prospective, controlled trial by Muthukumarswamy et al. ${ }^{16}$ examined the use of topical phenytoin versus control therapy in 100 non -insulin dependent diabetic patients with foot ulcers. In the control group $(\mathrm{n}=50)$, a sterile occlusive dressing was applied daily. In the phenytoin group $(\mathrm{n}=50)$, phenytoin powder was applied in a "thin layer" to the ulcer surface, and then dry dressing applied daily. Mean healing time was 21 days in the phenytoin group compared to 45 days in the control group ( $<<0.05 \%)$.

Tauro LF et al. ${ }^{67}$ observed 200 patients with diabetic ulcers. Hundred patients underwent topical phenytoin dressing while remaining underwent conventional wound care. The results were compared after 14 days. In study group, mean rate of granulation tissue formation was $87.94 \%$, mean graft take up was $92.31 \%$ and mean hospital stay was 32.26 days with negative culture sensitivity was $70 \%$. The control group showed, the mean rate of granulation tissue formation was $74.64 \%$, the mean graft take was $86.15 \%$ of total ulcer surface area and mean hospital stay was 54 days with negative culture sensitivity was $54 \%$. They concluded that topical phenytoin aids in faster healing of diabetic wounds with better graft take up and decreased hospital stay.

A study conducted by Pai et al. ${ }^{65}$ also showed good granulation tissue with topical phenytoin. 
Diabetic foot ulcer infections account for the largest number of proximate nontraumatic lower extremity amputations (BKA, AKA). Studies have shown that phenytoin stimulates fibroblast proliferation, decreases collagenase activity, increases epidermal and keratinocyte growth factor receptors, accelerates initial inflammatory responses, induces new vessel formation, speeds the decrease of microbial colonies and improves healing. It has been well documented in the literature that diabetic foot infections are polymicrobial in nature, but gram positive cocci were the predominant isolates in our study. We also isolated good number of aerobic gram negative organisms. There have been similar reports from studies which were done in north India. The isolation rate of aerobic gram negative bacilli was relatively less in many of the western reports. ${ }^{66}$

Phenytoin has been used as an adjuvant for accelerating wound healing since ancient times and number of clinical studies have indicated that phenytoin decreases the bacterial load of wounds ${ }^{9,12,13,16}$. Topical phenytoin was reported to eliminate Staphylococcus aureus, E. coli, Klebsiella spp. and Pseudomonas spp. from wounds within 7-9 days ${ }^{12}$

Clinical studies using topical phenytoin therapy suggest that it may be useful for the treatment of both acute and chronic wounds of various aetiologies, but some studies do not support the use of phenytoin in the treatment of diabetic foot ulcers ${ }^{68}$.

Pendse $^{20}$ showed that the wound area reduction was greater in the phenytoin group than in controls. Fifty percent of phenytoin-treated wounds had negative cultures by day 7 , as compared to $17 \%$ among controls. $72.5 \%$ phenytoin-treated ulcers had healed completely versus $28.5 \%$ controls.

In study conducted by Pai MR et $\mathrm{al}^{65}$ the mean percentage reduction of ulcer area was significantly more than that in the control group. $(\mathrm{p}>0.05)$. The mean difference between pretreatment and post treatment values (in $\mathrm{cm}^{2}$ ) of ulcer area was $6.45 \mathrm{~cm}^{2} \pm 1.53 \mathrm{vs} 5.44 \mathrm{~cm}^{2} \pm 1.49$. The phenytoin group showed a slight acceleration of effect as compared to the control group. The mean duration of hospital stay in phenytoin group was 20.04(9.141) days, whereas in control group, it was 26.10 (5.701) days. This difference was statistically significant.

Our observations regarding mean hospital stay were similar to observations of Muthukumarasamy MG et al ${ }^{16}$, Ritu Pai, who showed that in phenytoin group, mean healing time was 21 days versus 45 days in control group, in which sterile occlusive dressing was used. Most of the patients in both phenytoin and conventional groups had to undergo either split thickness skin graft or delayed primary suturing as a definitive procedure after initial debridement or incision and drainage. No post-operative complications were noted in patients treated with phenytoin.

Phenytoin (diphenylhydantoin or Dilantin) has been investigated as a treatment for more than 100 diseases. Numerous allergy and proliferative, idiosyncratic cutaneous side effects have been reported with its use $^{6}$. A frequent observed and unwanted side effect of phenytoin, an anticonvulsant medication, is gingival hyperplasia, especially in children ${ }^{8}$. This side effect suggested that phenytoin can induce the growth of connective tissue, and may have the ability to promote wound healing. In 1939 Kimball and Horan first observed that gingival hyperplasia occurred in some patients treated with phenytoin. This stimulated the first controlled clinical trial in 1958, which found that the periodontal patients with surgical wounds who were pretreated with oral phenytoin had less inflammation, less pain, and accelerated healing when compared with controls $^{30}$. Phenytoin has been investigated to treat ulcers in epidermolysis bullosa and other inflammatory conditions. Since then, the effectiveness of topical phenytoin has been confirmed by several clinical trials for different types of wounds. The earliest clinical study of phenytoin in cutaneous wound healing used oral phenytoin sodium to treat venous stasis ulcers in 28 patients in a double-blind, placebo-controlled trial ${ }^{11}$.

Phenytoin promotes wound healing by following mechanisms. They are: stimulation of fibroblast proliferation, enhancing the formation of granulation tissue, decreasing collagenase activity, inhibition of glucocorticoid activity, direct or indirect antibacterial activity by affecting inflammatory cells, neovascularization ${ }^{16,61,79,26}$ and phenytoin increases gene expression of the platelet derived growth factor $\beta$ chain in macrophage and monocytes ${ }^{82}$.

A number of clinical studies indicate that phenytoin decreases the bacterial load of wounds ${ }^{13,14,16}$. Topical phenytoin was reported to eliminate Staphylococcus aureus, E. coli, Klebsiella and Pseudomonas from wounds within 7 9 days ${ }^{12}$ In a guinea pig model of wound healing, it was found that phenytoin more readily cleared gram negative organisms than gram positive bacteria from wounds ${ }^{14}$. It is not known if phenytoin has intrinsic antibacterial activity, or whether the effect of phenytoin on the bacterial load of wounds is mediated indirectly by effects on inflammatory cells and neovascularization ${ }^{12}$. Local pain relief has also been observed with topical phenytoin therapy, which can be explained by its membrane-stabilizing action and the reduced inflammatory response ${ }^{84,81}$. Facilitation of nerve regeneration has also been reported with phenytoin ${ }^{12}$. This explains why in our study, phenytoin (study) group had negative bacterial culture when compared to povidone iodine (control) group. 
The prospective, controlled trial by Muthukumarswamy et al. ${ }^{16}$ examined the use of topical phenytoin versus control therapy in 100 non-insulin dependent diabetic patients with foot ulcers. In the control group $(n=50)$, a sterile occlusive dressing was applied daily. In the phenytoin group $(n=50)$, phenytoin powder was applied in a "thin layer" to the ulcer surface, and then dry dressing applied daily. Mean healing time was 21 days in the phenytoin group compared to 45 days in the control group $(\mathrm{p}<0.05 \%)$. A study conducted by Pai et al. ${ }^{65}$ showed good granulation tissue with topical phenytoin which was similar to this present study.

\section{Reported Side Effects Of Topical Phenytoin Preparations}

Topical phenytoin used in wound therapy appears to be well tolerated. Its adverse effects are mild and infrequent. Some patients have a transient burning sensation when the powder is initially applied, but this can be prevented by using pure phenytoin powder instead of phenytoin sodium. A generalized rash that resolved when treatment was stopped has also been reported ${ }^{82}$. Hypertrophic granulation tissue was noted in 10 36 percent of patients in two studies ${ }^{13,16}$ This is reversed by stopping treatment, and it is suggested that stopping treatment when the wound area is covered with a granulation base can prevent this effect. Systemic absorption of topical phenytoin is not significant. Most studies that have monitored serum phenytoin levels during topical application have shown the levels to be undetectable. Only one case report showed significant levels of serum phenytoin after topical phenytoin ${ }^{61}$.

Wound dressings have evolved from the status of providing physical protection to the raw surface, absorbing exudates and controlling local infections by local medications to the level of providing adequate environment promoting wound healing. This has been achieved by modern wound dressing equines promoting granulation tissue formation.

The concept of moist wound dressings which came into vogue in 1960 which revolutionized wound care .This led to further research in this direction leading to influx of many products.People have tried various non conventional topical agents in wound healing such as aleo vera, antacids, benzoyl per-oxide ,collagen ,gentian violet, impregnated guaze, insulin, mercurochrome oxygen therapy, sugar and vinegar. Each claiming a better wound healing rate than the others. As the concept of outcome based medicine evolved, the need for better wound dressing modality became more acute. Now wound dressing systems were compared not only on the basis of the rate of granulation tissue formed or the rate of wound healing but also on the cost and duration of hospital stay of the patient which was considered as a measure of the morbidity of the patient.

The study is similar to the study conducted by Ritu Raj et $\mathrm{al}^{68}$. The difference between the present study and Ritu Raj et al study is sample size was 100 , fifty in each group, mean age in study group was 55.71 yrs and 54.31 yrs in control. Graft takeup was $93.78 \%$ and $85.98 \%$ respectively. Hospital stay was 32.21 days in study group and 38.76 days in control group.

The study is similar to the study conducted by V.Patil et $\mathrm{al}^{66}$. The difference between the present study and V.Patil et al study is sample size was 100 , fifty in each group, mean age in study group was 48.50 yrs and 49.74 yrs in control. Graft takeup was $72.41 \%$ and $58.43 \%$ respectively. Hospital stay was 20.04 days in study group and 26.10 days in control group.

The study is similar to the study conducted by Leo $\mathrm{F}$ Tauro et $\mathrm{al}^{67}$. The difference between the present study and Leo F Tauro et al study is sample size was 200 , hundread in each group, mean age in study group was 50.11 yrs and 51.41yrs in control. Graft takeup was $92.31 \%$ and $86.15 \%$ respectively. Hospital stay was 32.26 days in study group and 54.00 days in control group.

In study made by me, the mean age group - in study group is $47.28 y$ rs and $49.20 y$ rs in control group Graft takeup was $91.78 \%$ and $75.48 \%$ respectively. Hospital stay was 30.04 days in study group and 45.10 days in control group.

This study was done as a prospective randomized controlled comparative study to compare the efficacy of topical phenytoin moist dressing to conventional moist wound dressing in management of diabetic ulcer.

Comparison with other similar studies:

\begin{tabular}{|c|c|c|c|c|c|c|c|c|}
\hline \multirow[t]{2}{*}{ Variable } & \multicolumn{2}{|c|}{ Leo F Tauro $^{67}(2013)$} & \multicolumn{2}{|c|}{ V.Patil $^{66}(2013)$} & \multicolumn{2}{|c|}{ Ritu $\mathrm{Raj}^{68}(2015)$} & \multicolumn{2}{|c|}{ Present Study } \\
\hline & Study & Control & Study & Control & study & control & Study & Control \\
\hline Sample Size & 100 & 100 & 50 & 50 & 50 & 50 & 50 & 50 \\
\hline Age & 50.11 & 51.41 & 48.5 & 49.74 & 55.71 & 54.31 & 47.28 & 49.20 \\
\hline $\begin{array}{l}\text { Rate of } \\
\text { Granulation }\end{array}$ & 87.94 & 74.64 & 78.3 & 73.50 & 88.21 & 71.32 & 85.21 & 70.32 \\
\hline $\begin{array}{l}\text { Mean graft } \\
\text { taken up }\end{array}$ & 92.31 & 86.15 & 72.4 & 58.43 & 93.78 & 85.98 & 91.78 & 75.48 \\
\hline Hospital Stay & 32.26 & 54.00 & 20.04 & 26.10 & 32.21 & 38.76 & 30.04 & 45.10 \\
\hline
\end{tabular}




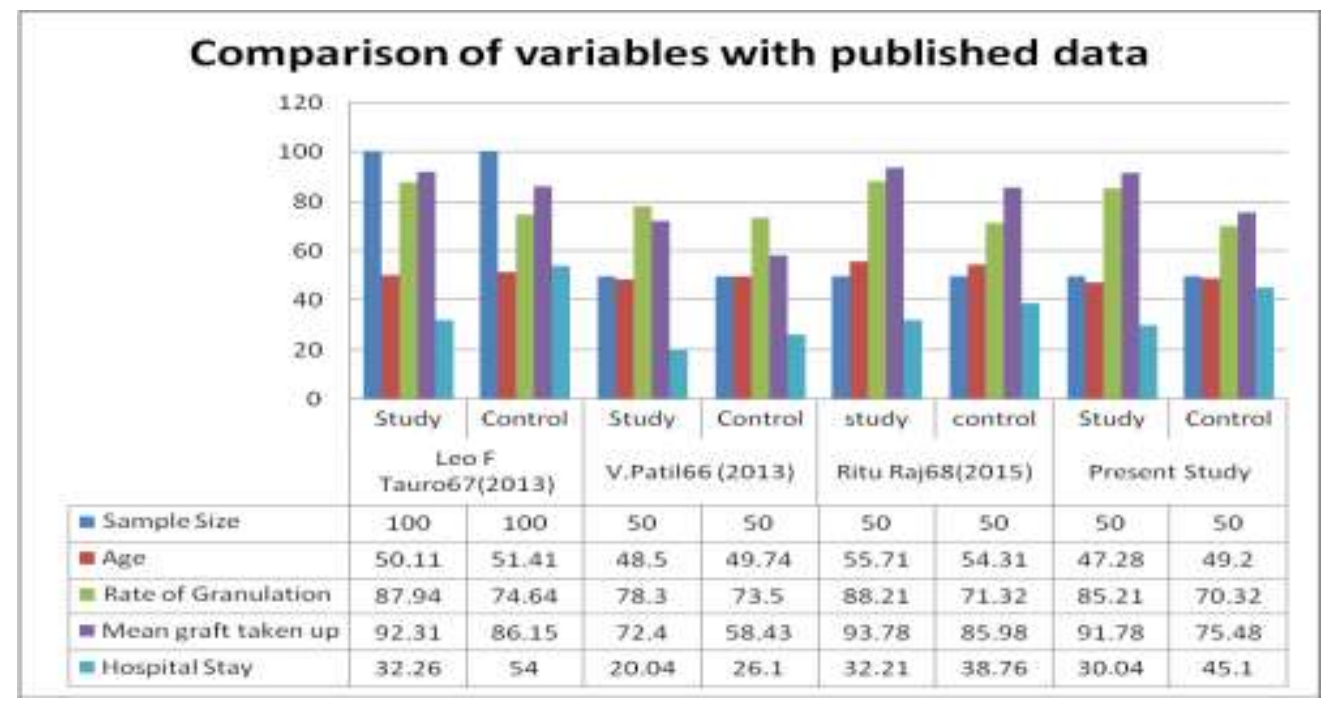

The quantitative assessment of the post operative parameters like wound .contraction, pain and residual raw ulcer area was also not included in the present study, which if included, might have given a much better analysis of the efficacy of topical phenytoin moist dressings as compared to conventional moist dressings

\section{Future Trends:}

The important areas where significant advances has occurred in chronic wound care are the development of wound dressing systems, which stimulate wound healing process by improved granulation tissue formation and the development of permanent composite skin replacement in the form of genetically engineered keratinocyte culture techniques and growth factors. The main problem of the latter technique is that it is still in the experimental phase and will not be available to common man in the near future.

Extensive research is going on in the development of artificial skin substitutes by combining cultured keratinocytes with artificially formed dermal analogues, namely Integra, AlloDerm, polygalactin mesh, human allogenic dermis etc., which has immense potential. It is only a matter of time before a 'successful approach to the management of chronic wounds is devised.

There are many types of dressings used to treat diabetic foot ulcers such as absorptive fillers, hydrogel dressings, and hydrocolloids. There is no good evidence that one type of dressing is better than another for diabetic foot ulcers. ${ }^{[46]}$ In selecting dressings for chronic non healing wounds it is recommended that the cost of the product be taken into account.

Hydrogel dressings may have shown a slight advantage over standard dressings, but the quality of the research is of concern. Dressings and creams containing silver have not been properly studied nor have alginate dressings. ${ }^{[50]}$ Biologically active bandages that combine hydrogel and hydrocolloid traits are available, however more research needs to be conducted as to the efficacy of this option over others.

\section{Limitations Of The Study}

The most important limitation of the present study is its sample size. Although a sample size of 100 patients is sufficient for statistical analysis, a randomized controlled comparative study with a much larger population may help to further substantiate the findings or reveal variations which were not observed in the present study.

The cost burden on the patient is also not analyzed in this study as this can be influenced by various factors other than the cost of dressings. Phenytoin dressing was found to be less expensive compared to conventional moist dressings ${ }^{16}$ The quantitative assessment of the post operative parameters like wound contraction, pain and residual raw ulcer area was also not included in the present study, which might have given a much better analysis of the efficacy of topical phenytoin moist dressings as compared to conventional moist dressings.

Clinical progress of an ulcer varies according to the location of the ulcer however we have not tabulated the location of the ulcers in the present study. From wound culture mixed bacterial flora was grown which was not included in this study. 
Skin graft take depends on lot of other inherent qualities of the ulcer, technical factors in skin grafting and the nutritional status of the patient which are not included in the present study.

For a real controlled study, it would be best to treat two ulcers in the same patient using one as a control which was not considered in our study since this is not a controlled trial.

\section{Conclusion}

In our present study it was concluded that the rate of granulation tissue formation, overall graft survival and patient compliance was better in topical phenytoin dressing group as compared to conventional dressing group.

It was also seen that the overall hospital stay and post operative complications were less in the topical phenytoin dressing group. Thus, topical phenytoin moist wound dressing can be considered as a superior option in the management of diabetic ulcers.

But further studies with larger population will be needed in the future before topical phenytoin dressing can be added to the wide spectrum of treatment modalities available in the management of diabetic ulcers and ulcers of other etiology.

\section{References}

[1]. Boulton AJ. The diabetic foot: a global view. Diabetes Metab Res Rev. 2000; 16 Suppl 1:S2-5. PubMed

[2]. Centers for Disease Control and Prevention (CDC). History of foot ulcer among persons with diabetes-United States, $2000-2002$. MMWR Morb Mortal Rep 2003; 52:1098-1102.

[3]. Ratner D. Skin grafting. Semin Cutan Med Surg 2003; 22(4):295-305.

[4]. Calhoun J.H., Overgaard K.A., Stevens C.M., Dowling J.P., and Mader J.T., 2002, Diabetic foot ulcers and infections: Current concepts, Adv. Skin Wound Care, 15: 31-42 (quiz 44-45)

[5]. Younes N., Albsoul A., Badran D., and Obedi S., 2006, Wound bed preparation with 10 percent phenytoin ointment increases the take of split-thickness skin graft in large diabetic ulcers, Dermatol Online 1, 12: 5

[6]. Meritt H.H., and Putnam T.J., 1938, Sodium diphenyl hydantoinate in the treatment of convulsive disorders, JAMA, 111:1068-1073

[7]. Silverman A.K., Fairley J., and Wongs R.C., 1988, Cutaneous and Immunologic reactions to phenytoin, J. Am. Acad. Dermatol., 18: 721-741

[8]. Bethedsa M.D., ASHP drug information 2001, American Society of Health System Pharmacists, 2001, P2081

[9]. el Zayat S.G., Preliminary experience with topical phenytoin in wound healing in a war zone, Mil Med., 1989;154: 178-180 PMid:2499825

[10]. Rhodes R.S., Heyneman C.A., Culbersten V.L., Wilson S.E., and Phatak H.M., 2001, Topical phenytoin treatment of stage II decubitus ulcers in the elderly, Ann Pharmaco therapy, 35: 675-681

[11]. Simpson G.M., Kunz E., and Slafta J., 1965, Use of diphenylhydantoin in treatment of leg ulcers, N Y State J Med., 65:886-888 PMid:14265330

[12]. Modaghegh S., Salchian B., Tavassoli M., Djamshidi A., and Rezai A.S., Use of phenytoin in healing of war and non war wounds, a pilot study of 25 cases, Int. J. Dermatol, 1989,28: 347-350 PMid:2666326

[13]. Pendse A.K., Sharma A., Sodani A., and Hada S., 1993, Topical phenytoin in wound healing, Int. J. Dermatol., 32: 214-217 PMid: 8444538

[14]. Lodha S.C., New application of an old drug: topical phenytoin for burns, J. Burns care Rehabil., 1991,12: 96

[15]. Bansal N.K., and Mukul, 1993, Comparison of topical phenytoin with normal saline in the treatment of chronic trophic ulcers in leprosy, Int. J. Dermatol., 34: 210-213

[16]. Muthukumarasamy MG, Sivakumar G, Manoharan G.Topical phenytoin in diabetic foot ulcers. Diabetes Care. 1991; $14: 909-11$.

[17]. Oluwatosin OM, Olabanji JK, Oluwatosin OA, Tijani LA, Onyechi HU. A comparison of topical honey and phenytoin in the treatment of chronic leg ulcers. Afr J Med Med Sci. 2000; 29:31-4.

[18]. Bhatia A, Prakash S. Topical phenytoin for wound healing. Dermatol Online J. 2004; $10(1): 5$.

[19]. Brem H, Lyder C. Protocol for the successful treatment of pressure ulcers. Am J Surg 2004; 188(1A Suppl):9-17.

[20]. Pendse S. Understanding diabetic foot. Int J Diabetes Dev Ctries. 2010;30:75-79. [PMC free article]

[21]. Laughlin RT, Calhoun JH, Mader JT. The diabetic foot. Am Acad Orthop Surg. 1995;3:218-25.

[22]. Harrison's Principle of Internal Medicine: Diabetes Mellitus. 16edn. Vol 2. USA: McGraw-Hill; 1999. pp. $2109-37$.

[23]. DaCosta ML, Regan MC, al Sader M, Leader M, Bouchier-Hayes D. Diphenylhydantoin sodium promotes early and marked angiogenesis and results in increased collagen deposition and tensile strength in healing wounds. Surgery. 1998;123:287-93.

[24]. Kato T, Okahashi N, Kawai S, Kato T, Inaba H, Morisaki I, Amano A. Impaired degradation of matrix collagen in human gingival fibroblasts by the antiepileptic drug phenytoin. J Periodontol. 2005;76:941-50.

[25]. Moy LS, Tan EM, Holness R, Uitto J. Phenytoin modulates connective tissue metabolism and cell proliferation in human skin fibroblast cultures. Arch Dermatol. 1985;121:79-83.

[26]. Genever PG, Cunliffe WJ, Wood EJ. Influence of the extracellular matrix on fibroblast responsiveness to phenytoin using in vitro wound healing models. Br J Dermatol. 1995;133:231-5.

[27]. Swamy SM, Tan P, Zhu YZ, Lu J, Achuth HN, Moochhala S. Role of phenytoin in wound healing: microarray analysis of early transcriptional responses in human dermal fibroblasts. Biochem Biophys Res Commun. 2004;314:661-6.

[28]. Lodha SC, Lohiya ML, Vyas MCR, Bhandari Sudha, Goyal RR, Harsh MK. Role of phenytoin in healing large abscess cavities. Br J Surg. 1991;78:105-8.

[29]. Liza R. Braun Diabetic Foot Ulcer : An evidence - based Treatment update American Journal of Clinical Dermatology July 2014, Volume 15, Issue 3, pp 267-281

[30]. Shapiro M. Acceleration of gingival wound healing in non-epileptic patients receiving diphenylhydantoin sodium (Dilantin, Epanutin). Exp Med Surg 1958; 16: 41-53. PubMed

[31]. Swann WP, Swenson HM, Shafer WG. Effects of dilantin on the repair of gingival wounds. J Periodontol 1975; 46(5):302-5. PubMed 
[32]. Madden JW. Textbook of Surgery, The Biological Basis of Modern Surgical Science. 11 th ed. Philadelphia: WB Saunders and Company; 1977. p.271

[33]. Muldner GD, Haberer PA, Jeter KF. Clinician's Pocket Guide to Chronic Wound Repair. 4th ed. Springhouse: Springhouse Corporation; 1998: p 85. .

[34]. Cohen IK. A Brief History of Wound Healing.l st ed. Yardley, PA: Oxford Clinical Communications Inc.; 1998.

[35]. Helling TS, Daon E. The Great War, Antoine Depage, and the1 resurgence of debridement. Annals of Surgery 1998; 228: 173-81

[36]. Cohen IK, Diegelmann RF, Crossland MC. Principles of Surgery. 6th ed. New York: McGraw Hill Inc.; 1994. p.279.

[37]. Winter GD. Formation of the scab and the rate of epithelialization of superficial wounds on the skin of young domestic pig. Nature 1962;193:293-4.

[38]. Kimball OP, Horan TN. The use of Dilantin in the treatment of epilepsy. Ann Intern Med 1939; 13:787-93.

[39]. Goebil RW. Sodium diphenylhydantoin association with oral healing. J Oral Surg 1972; 30; 191-5.

[40]. Shafer WG, Beatty RE, Davis WB. Effect of Dilantin sodium on tensile strength of healing wounds. Proc Soc Exp Biol Med 1958; 98:348-50.

[41]. Kolbert GS. Oral diphenylhydantoin in corneal wound healing in the rabbit. Am J Opthamol 1968; 66:736-8.

[42]. Sklans S, Taylor RG, Shklar G. Effect of diphenylhydantoin sodium on healing of experimentally produced fractures in rabbit mandibles. J Oral Surg 1967; 25:310-9.

[43]. Gudmundson C, Lidgren L. Does diphenylhydantoin accelerate healing of fractures in mice? Acta Orthop Scand 1973; 44:640-9.

[44]. Frymoyer JW. Fracture healing in rats treated with diphenylhydantoin(dilantin). J Trauma 1976; 16:368-70.

[45]. Kuebel MA, Yeager VL, Taylor JJ.Effect of phenytoin and/or beta-aminopropionitrile on surgically induced periosteal wound. J Exp Pathol 1985; 2:99-109.

[46]. Bansal NK, Mukul. Comparison of topical phenytoin with normal saline in the treatment of chronic trophic ulcers in leprosy. Int J Dermatol 1993; 32:210-13.

[47]. Malhotra YK, Amin SS. Role of topical phenytoin in trophic ulcers of leprosy in India. Int J Leprosy 1991; 59:337-8.

[48]. Menezes J, Rajendran A, Jacob AJW, Vaz M. The use of topical phenytoin as an adjunct to immobilization in the treatment of trophic leprosy ulcers. Southeast Asian J Trop Med Public Health 1993; 24:340-42.

[49]. Bogaert H, Saleta B, Sanchez E, Garcia B. Trophic leprosy ulcers: Treatment with topical and systemic phenytoin. Int J Dermatol 1990; 29:156-7.

[50]. El Zayat SG. Preliminary experience with topical phenytoin in wound healing in a war zone. Mil Med 1989; 28:347-50.

[51]. Lodha SC, Lohiya ML, Vyas MCR, Sudha Bhandari, Goyal RR, Harsh MK. Role of phenytoin in healing large abscess cavities. Br J Surg 1991; 78:105-8.

[52]. Mendiola-González JF, Espejo-Plascencia I, Chapa-Alvarez JR, Rodriguez-Noriega E. Sodium diphenylhydantoin in burns: effects on pain and healing (letter). Invest Med Int 1983; 10:449-51.

[53]. Yadav JK, Singhvi AM, Kumar N, Garg S. Topical phenytoin in the treatment of split-thickness skin autograft donor sites: a comparative study with polyurethane membrane drape and conventional dressing. Burns 1993; 19:306-10.

[54]. Bauer EA, Cooper TW, Tucker DR, Esterly NB. Phenytoin therapy of recessive dystrophic epidermolysis bullosa. N Engl J Med 1980; 303: 776-781.

[55]. Cooper TW, Bauer EA. Therapeutic efficacy of phenytoin in recessive dystrophic epidermolysis bullosa. Arch Dermatol 1984; 120:490-95.

[56]. Abahussein AA, al-Zayir AA, Mostafa WZ, Okoro AN. Recessive dystrophic epidermolysis bullosa treated with phenytoin. Int J Dermatol 1992; 31:730-732.

[57]. Caldwell-Brown D, Stern RS, Lin AN, Carter DM. Lack of efficacy of phenytoin in recessive dystrophic epidermolysis bullosa. N Engl J Med 1992; 327:163-167.

[58]. Masgrau-Peya E, Lacour M, Salomon D. Topical phenytoin accelerates healing in epidermolysis bullosa simplex. Dermatology 1995; 190: 254.

[59]. McAnally LE, Thompson D. Use of phenytoin for wound healing. Hospital Pharmacy 1992; 27:649-50.

[60]. Talas G, Brown RA, McGrouther A. Role of phenytoin in wound healing-a wound pharmacology perspective. Biochem Pharmacol 1999; 57:1085-94.

[61]. Anstead GM, Hart LM, Sunahara JF, Liter ME. Phenytoin in wound healing. Ann Pharmacol 1996; 30:768-75.

[62]. Shafer WG. Effect of Dilantin sodium on various cell lines in tissue culture. Proc Soc Exp Biol Med 1961; 108:694-96.

[63]. Vijayasingham SM, Dykes PJ, Marks R. Phenytoin has little effect on in vitro models of wound healing. Br J Dermatol 1991; 125:136-9.

[64]. Allen LV. Phenytoin topical powder for wounds. US Pharmacist 1996; 84:86.

[65]. Pai M, Sitaraman N, Kotian M S. Topical phenytoin in diabetic ulcers: A double blind controlled trial. Indian J Med Sci [serial online] 2001 [cited 2015 Oct 4];55:593-9.

[66]. Vijaya Patil, ${ }^{1}$ Rashmi Patil Topical Phenytoin Application in Grade I and II Diabetic Foot Ulcers: A Prospective Study J Clin Diagn Res. 2013 Oct; 7(10): 2238-2240.

[67]. Leo F. Tauro, Prathvi Shetty, Nita T. Dsouza, Saleem Mohammed, Suresh Sucharitha Phenytoin vs Conventional Wound Care in Diabetic Ulcers International Journal of Molecular Medical Science, 2013, Vol. 3, No. 8.

[68]. Rituraj Sunil Aggarwal Topical Phenytoin: Role in Diabetic Ulcer Care International Journal of Interdisciplinary and Multidisciplinary Studies (IJIMS), 2015, Vol 2, No.6, 93-97. 93 Available online at http://www.ijims.com ISSN: 2348 - 0343.

[69]. Wagner FW. The dysvascular foot: a system of diagnosis and treatment. Foot Ankle. 1981;2:64-122.

[70]. Pai DR,Madan SSTechniques in Chronic Wound Management: Review of the Literature and Recent Concepts.J Nov Physiother (2013) 3: 134.

[71]. Kramer A, Hübner NO, Weltmann KD, Lademann J, Ekkernkamp A, et al. Polypragmasia in the therapy of infected woundsconclusions drawn from the perspectives of low temperature plasma technology for plasma wound therapy. GMS Krankenhhyg Interdiszip (2008) 3: Doc13.

[72]. Laroussi M (2009) Low-temperature plasmas for medicine? IEEE Trans Plasma Sci 37: 714-725.

[73]. Dinh T, Elder S, Veves A (2011) Delayed wound healing in diabetes: considering future treatments. Diabetes Manage 1: 509-519.

[74]. Wang CJ, Wu RW, Yang YJ (2011) Treatment of diabetic foot ulcers: a comparative study of extracorporeal shockwave therapy and hyperbaric oxygen therapy. Diabetes Res Clin Pract 92: 187-193.

[75]. Moretti B, Notarnicola A, Maggio G, Moretti L, Pascone M, et al. (2009) The management of neuropathic ulcers of the foot in diabetes by shock wave therapy. BMC Musculoskelet Disord 10: 54 .

[76]. Carvalho Pde T, Silva IS, Reis FA, Perreira DM, Aydos RD (2010) Influence of ingaalp laser (660nm) on the healing of skin wounds in diabetic rats. Acta Cir Bras 25: 71-79. 
[77]. Landau Z, Migdal M, Lipovsky A, Lubart R (2011) Visible light-induced healing of diabetic or venous foot ulcers: a placebocontrolled double-blind study. Photomed Laser Surg 29: 399-404.

[78]. Villela DL, Santos VL (2010) Evidence on the use of platelet-rich plasma for diabetic ulcer: a systematic review. Growth Factors 28: 111-116.

[79]. Lacci KM, Dardik A (2010) Platelet-rich plasma: support for its use in wound healing. Yale J Biol Med 83: 1-9.

[80]. Talas G, Brown RA, McGrouther DA. Role of phenytoin in wound healing--a wound pharmacology perspective. Biochem Pharmacol. 1999;57:1085-94.

[81]. Dill RE, Miller EK, Weil T, Lesley S, Farmer GR, Iacopino AM. Phenytoin increases gene expression for platelet-derived growth factor B chain in macrophages and monocytes. J Periodontol. 1993;64:169-73.

[82]. Margolis DJ, Lewis VL. A literature assessment of the use of miscellaneous topical agents, growth factors, and skin equivalents for the treatment of pressure ulcers. Dermatol Surg. 1995;21:145-8.

[83]. Rhodes RS, Heyneman CA, Culbertson VL, Wilson SE, Phatak HM. Topical phenytoin treatment of stage II decubitus ulcers in the elderly. Ann Pharmacother. 2001;35:675-81.

[84]. Rothmeier J, Froscher W. Connective tissue changes during long term anticonvulsive therapy. Fortschr Med. 1989;107:743-7.

[85]. Lefebvre EB, Haining RG, Labbe RF.Coarse facies, calvarial thickening and hyperphosphatasia associated with long-term anticonvulsant therapy. N Engl J Med. 1972;286:1301-2.

[86]. Falconer MA, Davidson S. Coarse features in epilepsy as a consequence of anticonvulsant therapy. Report of cases in two pairs of identical twins. Lancet. 1973;2:1112-4.

[87]. Herberg KP. Effects of diphenylhydantoin in 41 epileptics institutionalized since childhood. South Med J. 1977;70:19-24.

[88]. Livingston S, Peterson D, Boks LL. Hypertrichosis occurring in association with Dilantin therapy. J Pediatr 1955;47:351-2

[89]. Shaw J, Hughes CM, Lagan KM, Stevenson MR, Irwin CR, Bell PM. The effect of topical phenytoin on healing in diabetic foot ulcers: a randomized controlled trial. Diabet Med. 2011;28:1154-7. 